\title{
Trax4transition: Traversing the Songlines of a Career
} by Alex Byrne

\author{
A reflection on change and transition drawing on the \\ speaker's experience in Australian university libraries, in \\ the leadership of IFLA and now at the State Library of \\ New South Wales.
}

$\mathrm{I}$ start by acknowledging that we meet on the land of the Cadigal people of the Eora Nation and pay my respects to their elders, past and present and to any Aboriginal people present this evening. This is not an empty, ritualised statement but a profound statement of respect for people, history and tradition. It is a most appropriate practice for us, the keepers of knowledge. For it is our responsibility to gather, preserve, carry forward and make available knowledge. We do that in many ways from the emphasis on meeting community needs by public libraries to the great heritage collections with which I am entrusted at the State Library of New South Wales. My career until now has been in academic libraries which combine these imperatives, combining a major emphasis on meeting immediate study needs, just in time, with the construction of just in case collections to support research today and into the future and a responsibility to preserve the scholarly record, a responsibility which is now being extended to research data management at the same time as the concern to hold archival copies of publications declines.

Acknowledgement of country is also apt for this conference of the Australian and New Zealand Theological Library Association as it demonstrates a reverence for tradition and for understanding belief. Although I have not worked in theological libraries, this aspect has been important to me for two decades during which I have tried to provide some leadership in exploring how we librarians and archivists in the Western, and specifically AngloAmerican, tradition of professional practice can engage with the very different cosmologies and epistemologies of Indigenous peoples and to explore what that engagement would mean for our professional assumptions, norms and behaviours.

\section{Songlines}

You will all be familiar with the concept of 'songlines', popularised by Bruce Chatwin's 1987 book The songlines (London, Cape). In Aboriginal Australia, songlines are the traditional lines through country, believed to have been formed by ancestral beings, which shape geography, sustainability, relationships and behaviours. At a transactional level they guide gatherings for ceremony and trade - trade which can take shells, ochres and other valuable 


\section{"For those of us}

\section{in the memory}

business, 'songlines'

offers a suitable

expression for

the cultural

continuities that

we tend and to

highlight the

juxtapositions

and insights that

emerge when the

lines of knowledge

intersect." commodities across our ancient continent. At a more metaphysical level, the songlines are sung, preserving knowledge and tradition and guiding behaviour. Elders are entrusted with their songs and the accompanying narratives and iconography: they must ensure that those expressions of culture and belief are properly used and safely transmitted to successive generations.

Chatwin used the term to convey his marvelling at the continuity of such ancient beliefs and as a metaphor for his own peregrinations in which that restless soul traversed the world and its cultures in search of his own meaning.

For those of us in the memory business, 'songlines' offers a suitable expression for the cultural continuities that we tend and to highlight the juxtapositions and insights that emerge when the lines of knowledge intersect. It is also an apt expression for the routes we follow through our careers as they are 'sung' by interest, opportunity, ambition, need and family and intersected by accident.

\section{Songlines of a career}

My career has sung me and my family across Australia from Townsville to Canberra to Darwin to Sydney and across the world during my involvement with the International Federation of Library Associations and Institutions (IFLA).

As a young librarian, three years out of library school, I was fortunate to be entrusted with the responsibility to recommend how to integrate two library services when the Townsville College of Advanced Education was amalgamated into the adjoining James Cook University by government decree. A little later, I was appointed Deputy Librarian at the brand new Australian Defence Force Academy which was a brave initiative to educate officers for the Australian Army, Air Force and Navy together for the first time through a combined university and military program. These and other experiences prepared me for my first executive position, as the foundation University Librarian at the then new Northern Territory (now Charles Darwin) University in 1989. Then I moved to the University of Technology, Sydney (UTS) and now the State Library of New South Wales (State Library).

I took over a decade to successfully create a culture of innovation and change at the University of Technology, Sydney and I am now attempting to do the same but much faster at the State Library of New South Wales.

\section{Poles apart}

The University of Technology, Sydney and the State Library of New South Wales are located at opposite ends of the central business district of Sydney, Australia but poles apart in many respects.

UTS, not quite 25 years old as a university, is a middle sized Australian university of with a strong emphasis on professional studies and some 30,000 students. Its research strengths are 


\section{"During my time}

at James Cook

University, I was

also fortunate

to work with a

talented colleague

to introduce the

online searching

of research

bibliographic

databases. In those

pre-Internet days,

this opened up a

world of valuable

information to

researchers at a

university $1600 \mathrm{~km}$

from the nearest

other university

- or university

library." developing especially in some areas of science and technology and in contemporary humanities. The UTS University Library operates from two locations and is energetic and innovative with growing digital collections and services. Focussed on information access and learning, it offers a modern discovery layer, 40,000 current serials (about 98\% digital), growing collections of ebooks and other digital materials and some 600,000 printed books. It is heavily engaged with social media.

In contrast, the State Library traces its history back to 1826 and is highly collection oriented. Its collections of some 5.5 million items and $11 \mathrm{~km}$ of manuscripts are valued in total at AUD 2.2 billion. They include the world's foremost collections on Australia and Oceania. At present, however, the Library limits its collection of born digital material to that captured through the National Library of Australia's PANDORA program. ${ }^{1}$ Implementation of apps and specialised image viewers are beginning to complement and extend a concerted program to digitise the Library's core heritage materials. The State Library is also responsible for leading and supporting the statewide network of 374 public libraries and for promoting learning across the community, roles which demand that it demonstrate and foster innovation in the public libraries and in the delivery of educational activities.

\section{Early experiences}

My early experiences as a manager were formative. The opportunity to analyse and then recommend the best way to merge two quite different, medium sized, libraries taught me the importance of caring for people. It demonstrated to me that it is crucial to understand the needs of each individual in the work environment and to respect them. It is important to understand the dimensions of need and to ensure that all are addressed, especially in times of change when staff can feel threatened and may interpret situations quite differently from what the managers intend to say or believe they have expressed.

During my time at James Cook University, I was also fortunate to work with a talented colleague to introduce the online searching of research bibliographic databases. In those pre-Internet days, this opened up a world of valuable information to researchers at a university $1600 \mathrm{~km}$ from the nearest other university - or university library. This initiative offered a fine example of technological innovation which significantly changed behaviour. Launched just after the move from card catalogues to computer produced microfiche catalogues - long before online catalogues - this innovation heralded the evolution of the library from collection centred to access centred. Seizing the

1 The PANDORA Archive is a selective collection of web publications and websites relating to Australia and Australians. It includes materials that document the cultural, social, political life and activities of the Australian community and intellectual and expressive activities of Australians. (http://pandora.nla.gov.au/ overview.html) 
"So I had to develop a culture of change by valuing energy, enthusiasm and initiative and challenging habit. This was reinforced by celebrating success and learning from failure rather than punishing those responsible." moment, we also launched ourselves into creating databases relevant to local research concerns including the biology and management of the Great Barrier Reef. For many, these innovations challenged research habits and therefore had to be promoted and explained in ways which suited their fields. These experiences underlined the importance of not only managing but also explaining innovation.

Shifting to the Australian Defence Force Academy (ADFA), I continued to implement technological innovation in many areas, including the initiation of the Australian Literature database, AustLit. I gained one especially important insight when we were introducing our first integrated library management system and the serials librarian decided to retire rather than work with the new serials module, not through pique but rather through a sense of her own boundaries. It is important to respect individual's boundaries while also necessary to challenge them at times.

Another most important lesson at ADFA was the power of organisational culture. As I mentioned above, the creation of the Academy was a brave initiative to educate officers for the Australian Army, Air Force and Navy together. The Academy thus brought together the organisational cultures and mores of the three armed services, the civilian defence bureaucracy and the university faculty and library staff. It provided fertile ground for misunderstanding and hostility. As Deputy Librarian, I was effectively the chief operating officer and consequently had to work with representatives of each of these groups. By endeavouring to understand their culture and their priorities I managed to advance the interests of the Library and its clients - the cadets and the faculty - within the new Academy, while ensuring that all parties felt that their issues and concerns were recognised.

\section{Northern Territory University}

Being appointed as the foundation University Librarian at the new Northern Territory University was a tremendous professional opportunity to create a new university library from two small and very limited college libraries. One of my most important responsibilities was to develop the idea of a university library in a remote institution in which few had any conception of the role and nature of a good university library, including few of the library staff. I thus had to cogently and persuasively express an inspiring vision. However, I also encountered an environment in which expectations were low and where there were ingrained habits and little appetite for change. So I had to develop a culture of change by valuing energy, enthusiasm and initiative and challenging habit. This was reinforced by celebrating success and learning from failure rather than punishing those responsible. Implementing these strategies demanded team efforts as we built our collections, IT systems, two new library buildings, our services and our relationships with academic staff and with students.

One example, a particularly important example, lay in our services 
"By taking proactive approaches to engagement with Aboriginal students and staff - such as working with them in their environment rather than expecting them to come to the Library - and backing talented Library staff, we turned this around to become exemplary in our relationships with Aboriginal students, staff and the broader community." to Indigenous students, a vitally important issue for NTU, located in an area with a large proportion of Aboriginal people. The University and its Library were under-serving the Aboriginal community and providing inadequate support for Aboriginal students. By taking proactive approaches to engagement with Aboriginal students and staff - such as working with them in their environment rather than expecting them to come to the Library - and backing talented Library staff, we turned this around to become exemplary in our relationships with Aboriginal students, staff and the broader community. This experience emphasised the crucial importance of being open and responsive to cultural diversity in our increasingly diverse societies.

\section{University of Technology, Sydney}

UTS University Library has earned a reputation across Australasia and beyond as an innovative library that welcomes change. That reputation was developed over a decade through strategies to overcome the constraints of limited budget, an initially bureaucratic internal culture and a bureaucratic and often unsupportive university administration. Those characteristics of the University continue to persist but the University Library has been largely insulated from them and is seen as a high achieving and highly responsive element of the University.

Key strategies to support innovation included building the necessary infrastructure, valuing diversity, encouraging risk taking and possible failure, celebrating creativity and success, and blocking inhibitors. As a result, UTS Library has 'punched above its weight' for many years, returning great benefits to the Library's clients and to the University through advanced services and superior access to scholarly information. There are many examples which extend from restructuring areas to bring in new professionals to encouragement for staff to express themselves within the Library, across the University and in professional forums. Taking risks with new technology, being on the 'bleeding edge', was important to moving forward quickly and to demonstrating that innovation was valued and its successful implementation would be celebrated. But small ideas were also important such as taking up the suggestion of a younger member of staff that the University Library participate in International Edible Books Day and, subsequently, that we introduce a 'Fun Day' for students. Both showed that we could do our job and achieve much while being light hearted and fun loving, indications of a collaborative and friendly workplace as well as a library which joyfully welcomes its clients.

The success of these strategies has, of course, been demonstrated in the success of the Library and is reflected in its reputation. My success in building a culture of change and innovation was strikingly demonstrated in my decision to pass the organisation and operation of the Library's planning process to a team of staff members without formal supervisory or management responsibility. Demonstrating 


\section{"In my view, a} profession must be founded on an ethical base and for a profession vitally concerned with access to information, that foundation

must encompass unhindered access and its counterpart, freedom of expression." trust in both the members of that team and the Library's staff in general, this approach loosened the Library's planning processes, generated a very strong plan and gained the ownership of the staff. It also discomfited some of our more rigid managers, which was not an unwelcome side effect.

\section{IFLA}

My approach to the challenge of fostering innovation and change in the libraries I have directed has also been informed by my experiences as the first chair of the Free Access to Information and Freedom of Expression (FAIFE) Committee and then as IFLA President-elect and President.

The IFLA I entered as a novice member two decades ago was a great international organisation but one bound by the constraints of its history and its self-imposed bureaucracy: it is significantly more nimble, responsive, inclusive and effective today. As the inaugural chair of FAIFE, I faced the challenge of introducing a new priority to IFLA, the recognition of the inalienable human right to know as a fundamental motivation for the work of the Federation and its members, library associations, libraries and similar organisations and those who work in them. For some, this priority lay well outside the professional domain with some suggesting that pursuing such goals should be the work of human rights organisations and not the peak international organisation for a profession which should limit itself to methods, standards, collaboration and the status of the profession. Clearly, I do not share that perspective. In my view, a profession must be founded on an ethical base and for a profession vitally concerned with access to information, that foundation must encompass unhindered access and its counterpart, freedom of expression.

Advocating for the human right to know, a fundamental principle, developed on my work to highlight the responsibility we have to recognise and support Indigenous peoples and their cultures. From my work in the area over the last two decades, embracing Indigenous issues has become for me a touchstone of our commitment to addressing wholeheartedly the information needs of all. As IFLA President-elect and President, I worked with President Kay Raseroka and other colleagues to broaden that program of recognising the principles on which we base our profession and developing the Federation's priorities and programs accordingly. Implementing these brave agendas - FAIFE and IFLA's 'Three Pillars' - across the breadth and diversity of IFLA were challenging projects which called on all the skills I have developed in my professional career. Addressing these big issues convinced me that, to meet the needs of our clients and to fulfil our broader social role, our practice must fully embrace innovation and change.

\section{State Library of New South Wales}

During my first year at the State Library I have recognised many 


\section{"At the State}

\section{Library, we take a} risk management

approach to intellectual

property rights.

... we take all

reasonable steps to

identify rights and

proceed to digitise,

make available

and permit use

unless we identify

rights which would

impede those

activities." of the same constraints as those I encountered on arrival at UTS, and indeed in my previous post at the Northern Territory University. They include limited and inflexible information technology, tired and inadequate building spaces, bureaucratic internal culture, ossified work practices and resistance to change in some areas and a heavy burden of external compliance. Most serious of all is that many staff have become unable to 'dare to dare', in other words they do not expect to be permitted to experiment and possibly fail. Over the four years of her tenure, my predecessor did much to address these constraints and her success is evident in many areas but more is to be done.

The key issue here is culture. If innovation is to be fostered and change embraced, it is essential to develop an ethos which values experiment and celebrates creativity. The workplace culture must become permissive, a culture in which 'all is permitted except that which is forbidden' and even the latter is open to debate. It needs to be a culture of respect, a culture which values diversity in all of its manifestations, including diversity of language, ethnicity, lifestyle, intellectual approach, age and gender. It needs to be a culture which does not overvalue rank so that all may speak their minds and contribute their ideas without inhibition. For those of us who work in bureaucratic contexts it can be difficult to develop such an ethos because the environment militates against it. That is the time when the leader must become protector, nurturing the seed of innovation by sheltering it from the dry blast of bureaucracy and the chill of compliance.

At the State Library, I am employing similar approaches to those I used in other institutions but feel a greater sense of urgency because we have so much unrealised potential and because we have, at this point in time, the welcome opportunity of an interested and supportive State Government, something which experience tells us that we should not take for granted.

Risk deserves particular mention. Many organisations are risk adverse in that they attempt to eliminate or at least minimise risk. This makes the organisations conservative and reactive, the major inhibitors of innovation and the willingness to embrace change. The better approach is to manage risk by identifying areas of risk, instigating strategies to mitigate risk and planning counter moves and recovery if adverse results eventuate. At the State Library, we take a risk management approach to intellectual property rights. While we do not wish to breach any rights, the copyright status of much of the content of our collections is unclear and sometimes impossible to determine. Rather than be risk adverse and consequently freeze access and use of those materials, we take all reasonable steps to identify rights and proceed to digitise, make available and permit use unless we identify rights which would impede those activities. We take this stance because we consider that there is a greater public interest in obtaining access to heritage materials than in inhibiting 


\section{"In my work as}

a manager and

leader, I try to

challenge habit and

promote innovation

and change

while respecting

individuals. I

endeavour to

express an inspiring

vision which values

energy, enthusiasm

and initiative and is

open and responsive

to cultural and

other diversity." it. In other words, the risk of not providing access exceeds the risk posed by unclear rights.

\section{Conclusion}

The songlines of my career have emerged from my experiences as a librarian, manager, executive, leader and family man. They have been informed by my experiences in many organisations, different parts of Australia and internationally. Those experiences and my attempts to engage with Indigenous issues relating to our vocation have given me a deep concern with culture, in all senses of the word. In my work as a manager and leader, I try to challenge habit and promote innovation and change while respecting individuals. I endeavour to express an inspiring vision which values energy, enthusiasm and initiative and is open and responsive to cultural and other diversity. We need to trust, support experimentation, manage risk, celebrate success and learn from failure. I would like to think we can be lighthearted and fun loving while focussed on outcomes. And, we must always hold tightly to, and advocate for, fundamental principles.
Dr Alex Byrne is a
professional librarian,
researcher and writer with
a deep interest in the roles
of memory institutions, the
complexity of issues relating
to Indigenous peoples and
transmission of knowledge.
He has been State Librarian
and Chief Executive of the
State Library of New South
Wales since September
2011 following positions
in library and university
management, most recently
at the University of

Technology, Sydney. Alex served for a decade in leadership positions with the International Federation of Library Associations and Institutions including President from 2005 to 2007. He enjoys travel and the bush, drawing and printmaking, and - inevitably - reading. 